\title{
Bleb incarceration following Ahmed valve surgery
}

This article was published in the following Dove Press journal:

International Medical Case Reports Journal

20 October 2016

Number of times this article has been viewed

\section{Fredric J Gross \\ Giovanni DiSandro}

Department of Ophthalmology, Eastern Virginia Medical School, Norfolk, VA, USA
Correspondence: Fredric J Gross

Department of Ophthalmology, Eastern Virginia Medical School, 7338 Millbrook

Road, Norfolk, VA 23505, USA

Fax + I 7573880355

Email heye5@aol.com

\begin{abstract}
Globe luxation is a painful and potentially vision-threatening condition in which the globe becomes trapped behind the eyelids requiring physician intervention in the emergency department or eye clinic. On presentation, the patient typically complains of an inability to close their eye, severe foreign body sensation, decreased vision, and significant eye pain. Although most visual symptoms are reversible and primarily result from exposure keratopathy, optic nerve damage, and permanent vision loss can occur from repeat or prolonged episodes of globe luxation. Risk factors include any congenital or acquired conditions that displace the globe anteriorly in the orbit and increased eyelid laxity that allows the globe to prolapse through the lid aperture. Typically, the precipitating event involves eyelid retraction during ophthalmic examination or an event that increases intraorbital pressure such as coughing or sneezing. Once the globe has luxated, the condition is typically worsened by blepharospasm and patients' attempts to close the eye that worsen the entrapment. In the current case, the patient had a large superotemporal filtering bleb following Ahmed valve surgery for uncontrolled glaucoma. While instilling her glaucoma medication, she retracted her eyelids sufficiently to pull the upper lid over her filtering bleb where it became entrapped causing a similar presentation to globe luxation. Traditional methods of repositioning the globe were unsuccessful. Bleb needling was ultimately required to return the globe to a normal position.
\end{abstract}

Keywords: luxation, globe, glaucoma

\section{Introduction}

A 56-year-old African-American female presented to the emergency department with right eye pain and inability to close her eye following the instillation of her glaucoma drops (Figure 1). The patient had a history of endstage primary open-angle glaucoma and was 5 months status post Ahmed valve surgery right eye (OD) (model FP-7). Prior to this event, the patient had a large thick walled bleb in the superotemporal quadrant with an intraocular pressure of $16 \mathrm{mmHg}$ on Cosopt twice a day. The patient consented to the publication of this data and the associated images.

On examination, her vision was reduced to Hand Motion OD from her baseline of Counting Fingers. Applanation tonometry showed an intraocular pressure of $35 \mathrm{mmHg}$ OD and $16 \mathrm{mmHg}$ left eye (OS). Slit lamp examination revealed an exuberant thick walled bleb in the superotemporal quadrant of the right eye with the upper eyelid retracted tightly behind it. The bleb was injected but seidel negative and extended from the limbus posteriorly for approximately $16 \mathrm{~mm}$ and circumferentially from 8:30 to 1:00 (Figure 1). The lower lid appeared to be in the normal position. There was significant exposure keratopathy, but the eye was otherwise quiet. Computed tomography scan of the orbits (Figure 2) showed shallow orbits with no intraorbital masses, rectus muscle 


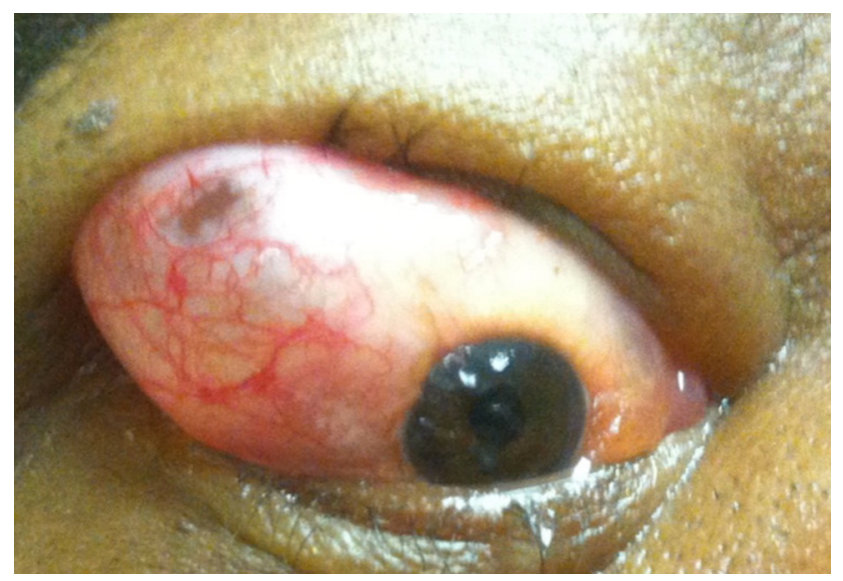

Figure I The upper eyelid is trapped behind an engorged and very large superotemporal filtering bleb.

Note: The lower eyelid is in normal position.

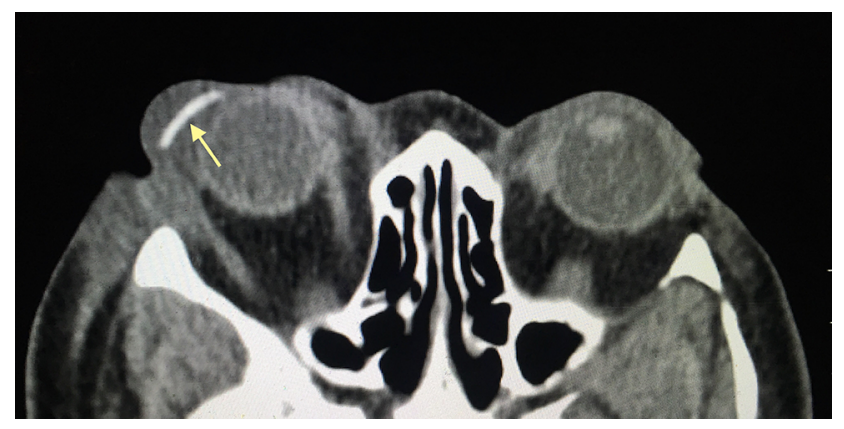

Figure 2 Computed tomography image of the orbit demonstrates the superiorly subluxed globe with a superotemporal Ahmed valve (arrow).

Notes: Both globes are normal in size and shape. The orbits are shallow with no evidence of intraorbital tumor, rectus muscle enlargement, or inflammatory process. The right globe appears to be $2 \mathrm{~mm}$ proptotic compared to the left.

enlargement, or inflammatory changes. The Ahmed valve was visualized in the superior temporal quadrant. The right globe appeared to be $\sim 2 \mathrm{~mm}$ proptotic compared to the left globe.

Repeat attempts to manually reposition the globe using standard techniques including posterior pressure on the globe combined with lid retraction, and the use of a Desmarres retractor to pull the upper lid anteriorly were unsuccessful. A lid block was not administered because the patient did have significant blepharospasm. Digital massage was performed through the upper lid in an attempt to soften the eye, however, this maneuver was uncomfortable to the patient and was unsuccessful. The patient initially refused surgical intervention and was placed on aggressive topical lubricants, oral acetazolamide, and topical aqueous suppressants overnight.

The next day, the patient was reexamined with no change in clinical appearance. The intraocular pressure was reduced to $20 \mathrm{mmHg}$ and repeat attempts to reposition the globe behind the upper eyelid were again unsuccessful. The options for surgical decompression in the operating room and bleb needling at the slit lamp were discussed with the patient. It was decided to surgically decompress the bleb by needling in an attempt to relieve the entrapment. Under topical anesthesia at the slit lamp, a 30-guage needle was passed transconjunctivally in the superonasal quadrant perforating the internal fibrous capsular wall of the bleb (Figure 3). This resulted in mild flattening of the filtering bleb and softening of the eye. Additional needling was also performed temporally further decompressing the bleb. The anterior chamber remained formed during and after both of these needling procedures. After needling, the bleb became significantly lower and more diffuse for $360^{\circ}$ and remained seidel negative. At this point, the globe was successfully reposited by pinching and pulling the upper eyelid anteriorly and up while placing gentle posterior pressure on the globe while the patient looked down (Figure 4). By the following day, the patient's exposure keratopathy had resolved and her vision and intraocular pressure returned to baseline. The patient was instructed not to retract her upper lid when instilling her eye drops in the future. No recurrences have occurred in 2 years of follow-up.

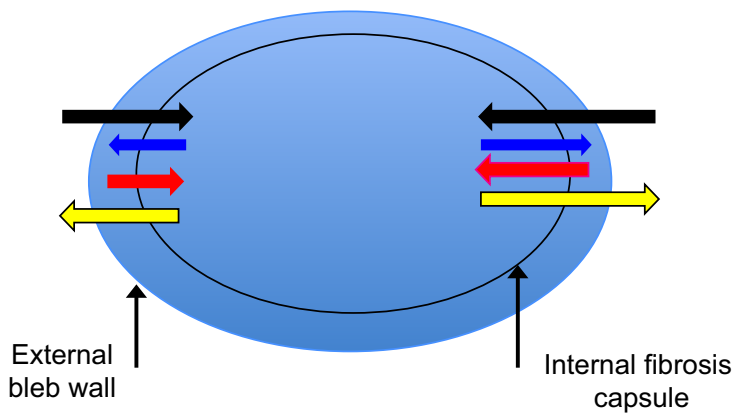

Figure 3 Bleb needling was performed with a 30 guage needle under topical anesthesia.

Notes: The needle is introduced I-2 mm from the bleb surface and advanced subconjunctivally until the internal fibrous capsule is perforated (black arrow). The needle is retracted without removing it from the subconjunctival space (blue arrow) and advanced again to perforate the capsule a second time (red arrow). The needed is then withdrawn from the eye (yellow arrow). Both nasal and temporal needling were performed.

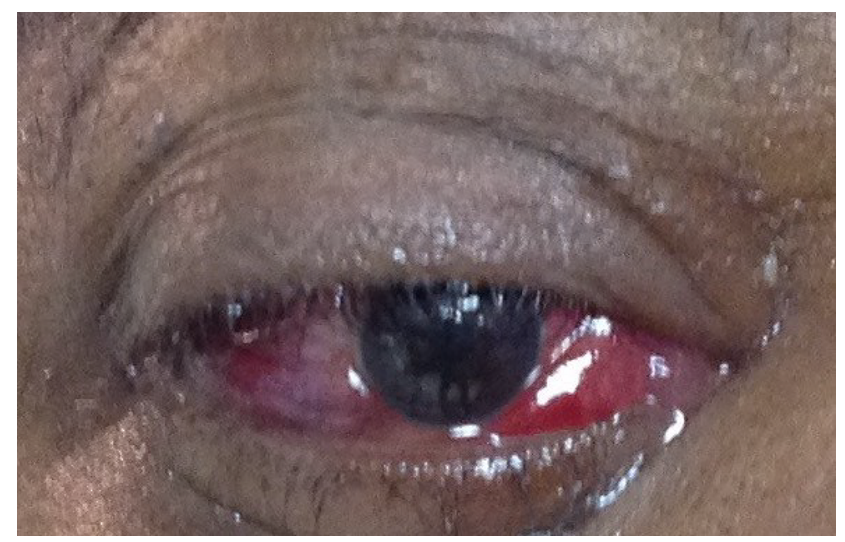

Figure 4 Postoperative appearance of the patient after needling and repositioning of the upper eyelid in front of the globe.

Note: The bleb can be seen to be diffuse for $360^{\circ}$. 


\section{Discussion}

Globe luxation is a relatively uncommon occurrence in which the eyelids become trapped behind the globe resulting in a painful emergency that can be vision threatening. ${ }^{1}$ In most cases, preexisting variations in orbital, eyelid, or extraocular muscle anatomy predispose the eye to prolapse by either anteriorly displacing the globe in the orbit or allowing easier displacement through the lid aperture. Some of these conditions include a congenitally shallow or malformed orbit, thyroid eye disease, orbital tumors, and floppy eyelid syndrome. ${ }^{2-4}$ Typically, globe luxation is associated with eyelid manipulation during ophthalmic examination or results from Valsalva maneuvers including coughing, sneezing, or nose blowing. Rarely, patients can voluntarily sublux their globe. ${ }^{1}$ Kunesh and Katz reported a case of globe luxation associated with contact lens insertion. ${ }^{5}$ In our patient, the presence of anatomically shallow orbits was the only identified predisposing factor and retraction of the upper lid during drop instillation was the precipitating event. It is noteworthy in our case that the lower lid was in a normal position at the time of presentation since in most cases of globe luxation both eyelids are involved. We believe that the isolated superior eyelid entrapment resulted from the upper eyelid passing beyond the equator of the globe and over the filtering bleb when the patient was retracting her eyelid to instill her glaucoma medication. Once the eyelid was trapped behind the filtering bleb, it could not spontaneously return to the normal position.

In most cases of globe luxation, the eye can be repositioned by pinching or retracting the upper eyelid and pulling it over the equator of the globe under topical anesthesia. ${ }^{6}$ In more difficult cases, a Desmarres retractor or similar instrument can be used to pull the upper eyelid forward while the patient looks downward. Additional use of oral or intravenous anxiolytics along with a lid block may also be helpful if there is significant blepharospasm or high patient anxiety. As previously mentioned, none of these standard maneuvers was successful in our patient until the bleb was needled. We theorize that once the superior eyelid became trapped behind the globe and bleb, posterior aqueous flow was blocked and resulted in further enlargement of the filtering bleb. This engorgement was preventing globe reduction by routine maneuvers. Bleb needing of encapsulated Ahmed valves is generally unsuccessful in achieving long-term reductions of intraocular pressure; it does, however, produce an immediate drop in intraocular pressure and creates a lower and more diffuse bleb. ${ }^{7}$ In our case, we were able to use this technique to decompress the engorged filtering bleb and release the incarcerated upper eyelid allowing for a successful globe repositioning.

The presence of large thick walled blebs in patients' shallow orbits and or flopping eyelids would appear to be a risk factor for globe prolapse or bleb incarceration. Because this bleb architecture is more common following Seton procedures, patients who have aqueous shunting procedures may be at greater risk from this complication. Had needling failed, the authors were considering a bleb revision to remove part of the thick fibrous capsule surrounding the Ahmed plate as an alternative method of decompression.

\section{Disclosure}

The authors report no conflicts of interest in this work.

\section{References}

1. Apostolopoulos M, Papaspirou A, Damanakis A, Theodossiadis G, Moschos M. Bilateral optic neuropathy associated with voluntary globe luxation and floppy eyelid syndrome. Arch Ophthalmol. 2004, 122(10):1555-1556.

2. Wood CM, Pearson AD, Craft AW, Howe JW. Globe luxation in histiocytosis X. Br J Ophthalmol. 1988;72(8):621-623.

3. Chandran G, Alexander T, Thomas A. Crouzon's disease with bilateral luxation of the globes. Indian J Ophthalmol. 1981;28(4):229-230.

4. Alexandrakis G, Tse DT, Chang WJ. Spontaneous globe luxation associated with floppy eyelid syndrome and shallow orbits. Arch Ophthalmol. 1999;117(1):138-139.

5. Kunesh JC, Katz SE. Spontaneous globe luxation associated with contact lens placement. CLAO J. 2002;28(1):2-4.

6. Tse DT. A simple maneuver to reposit a subluxed globe. Arch Ophthalmol. 2000;118(3):410-411.

7. Eibschitz-Tsimhoni M, Schertzer RM, Musch DC, Moroi SE. Incidence and management of encapsulated cysts following Ahmed glaucoma valve insertion. J. Glaucoma. 2005;14(4):276-279.
International Medical Case Reports Journal

\section{Publish your work in this journal}

The International Medical Case Reports Journal is an international, peer-reviewed open-access journal publishing original case reports from all medical specialties. Previously unpublished medical posters are also accepted relating to any area of clinical or preclinical science. Submissions should not normally exceed 2,000 words or
Dovepress

4 published pages including figures, diagrams and references. The manuscript management system is completely online and includes a very quick and fair peer-review system, which is all easy to use. Visit http://www.dovepress.com/testimonials.php to read real quotes from published authors. 